\title{
Capital intangível e direitos de propriedade intelectual: uma análise institucionalista
}

\author{
ALAIN HERSCOVICI *
}

Intangible capital and intellectual property rights: an analysis in terms of institutions. This paper deals with the main evolutions that explain the emergence of new institutional arrangements that characterize the post-fordism. (i) Hence, I will show that the property rights modifications bring forth new forms of competition; (ii) Also, I will make explicit the concrete expressions of this new competition, as well as how it translates itself in a sub-optimum allocation in the framework of the market game; (iii) I will study the modifications of externalities nature produced by technical progress; (iv) Finally, I will analyze the macroeconomic implications in regard to growth mechanisms and to capital nature.

Key-words: intellectual property rights; externalities; competition.

JEL Classification: D8; D71; B52.

É importante lembrar que as atividades efetuadas no mercado consistem em trocar um direito de propriedade ou de uso por uma remuneração (Bellon, 2004:317). No que diz respeito aos mercados estudados pela Ciência Econômica, é relativamente fácil identificar os direitos de propriedade ou de uso; ao contrário, no que concerne à informação e ao conhecimento, a identificação desses direitos é muito mais complexa e ambígua. A extensão da lógica mercantil às atividades ligadas à informação, ao conhecimento e às biotecnologias se traduz, concretamente, pela falta de uma definição clara e precisa dos critérios relativos à definição e ao objeto desses direitos de propriedade. Por outro lado, a importância crescente das produções imateriais nas atividades econômicas implica modificações importantes no que diz respeito à natureza de determinados mecanis-

\footnotetext{
* Doutor em Economia pelas Universidades de Paris I Panthéon-Sorbonne e de Amiens, Coordenador do Grupo de Estudo em Macroeconomia (GREM) do Departamento de Economia da UFES, Professor e Coordenador do Mestrado em Economia e Diretor da Associación Latina de Economia Política de la Información, Cultura y Comunicación (ULEP-ICC) e Pesquisador do CNPq. E-mail: alhersco.vix@terra.com.br. Submetido: março 2006; aceito: julho 2006.
} 
mos econômicos, de determinadas instituições e dos próprios determinantes do valor dos bens e dos serviços.

Os direitos de propriedade sempre foram objeto de uma atenção particular por parte dos economistas:

i) a teoria walrasiana da remuneração dos fatores de produção à sua produtividade marginal faz com que o lucro seja concebido como a remuneração dos serviços produtores do capital (Denis, 1974:507). Nessa perspectiva, o lucro é a remuneração do proprietário do capital, para imobilizar o capital durante determinado período. Trata-se de uma concepção do lucro e da taxa de juros baseada na "remuneração para a espera".

ii) Hoje, as teses de inspiração neoclássica concebem os direitos de propriedade intelectual (DPI) como um mecanismo capaz de desenvolver a inovação tecnológica e de maximizar a função de bem-estar social (North, 1981). Os DPI constituem assim a remuneração do serviço produtor fornecido pelo inovador.

A abordagem desenvolvida neste trabalho é diferente: numa primeira parte, analisarei as especificidades econômicas da informação e do conhecimento e mostrarei como elas tornam necessária uma modificação dos direitos de propriedade, das racionalidades econômicas e dos objetos sobre os quais esses direitos se exercem. Numa segunda parte, mostrarei como e por que a "nova economia" se caracteriza pela emergência de novas formas institucionais, principalmente no que diz respeito aos DPI e à concorrência. Após ter definido essas novas formas institucionais, mostrarei como elas modificam a natureza do capital e do progresso técnico, e explicam a configuração do regime atual de acumulação. É interessante notar que este tipo de reflexões se relaciona diretamente com o debate relativo à natureza do capital, no que diz respeito às diferentes formas de capital intangível.

\section{O POSICIONAMENTO TEÓRICO}

\section{Problemática e definição do objeto da análise}

As hipóteses de trabalho

No âmbito de uma abordagem realizada em termos de instituições, o mercado é concebido como uma combinação específica e historicamente determinada de elementos econômicos e extra-econômicos. O mercado não pode ser concebido como uma instância abstrata que funciona independentemente de determinadas normas sociais e simbólicas. Contrariamente à concepção neoclássica, o mercado não e constituído por agentes homogêneos que trocam bens e serviços (Arrow, 2000 (a): 246-247) e maximizam determinadas funções objetivas a partir de uma racionalidade substantiva definida fora de qualquer referência às normas sociais vigentes; da mesma maneira, o sistema de preços não fornece o conjunto das informações necessárias ao conjunto dos agentes econômicos. 
Os trabalhos de história, de antropologia e de sociologia econômicas ressaltam o fato que o mercado não pode funcionar concretamente sem determinados elementos extra-econômicos: as relações econômicas são "encaixadas" nas relações sociais (Karl Polanyi, 1983:79). ${ }^{1}$ A economia das convenções permite formular resultados semelhantes (Alain Rallet, 1999; Olivier Favereau, 1990): “A convenção é uma forma que permite coordenar interesses contraditórios que resultam de lógicas antagônicas mas que devem coexistir para poderem ser satisfeitos" (Alain Rallet, op. cit.:112). O sujeito econômico é um sujeito social cuja racionalidade e cujo sistema de valores é determinado a partir de variáveis extra-econômicas. As análises heterodoxas propõem-se a estudar esses processos de socialização e a mostrar como esses processos cumprem um papel fundamental nas diferentes modalidades de regulação econômica.

A escolha desse instrumental metodológico permite construir a seguinte problemática: quais são as principais modificações institucionais que caracterizam o pós-fordismo e a "nova economia"? Em que medida essas mudanças se traduzem por uma modificação da natureza da concorrência e dos direitos de propriedade? Finalmente, quais são as implicações dessas evoluções no que concerne à natureza do capital e do progresso técnico?2

As especificidades econômicas do conhecimento e da informação

A economia do conhecimento distingue dois tipos de conhecimento, o conhecimento tácito e o conhecimento codificado: o primeiro está diretamente ligado a determinados agentes ou instituições e não pode ser utilizado sem esse tipo de mediações. Ao contrário, o conhecimento codificado é despersonalizado, "descontextualizado", e fixado sobre determinado suporte material: o livro, o CD, a rede internet etc.; neste caso, o conhecimento é transformado em informação, sua utilização é muito mais ampla e não está diretamente ligada a determinado agente ou determinada instituição. A codificação do conhecimento implica, de fato, a existência de uma linguagem específica e de um suporte físico ou virtual também específico; permite, em uma certa medida, ampliar as modalidades de acesso a esse conhecimento e constitui a condição necessária para que ele se torne uma mercadoria (Foray, 2000:48), conforme ressalta a evolução da natureza e do campo de aplicação dos direitos de propriedade intelectual e industrial.

Finalmente, é interessante observar que, na tradição da economia clássica, o capital constante é concebido como trabalho que foi gasto no passado (Marx fala em trabalho cristalizado, Ricardo explica o paradoxo da teoria do valor a partir desse tipo de análise); se o conhecimento e a forma particular que ele assume no progresso técnico ou na técnica, podem ser considerados como uma acumulação de trabalho realizada no passado, a acumulação capitalista é o produto do

\footnotetext{
${ }^{1}$ Ver igualmente Bourdieu (2000) e Godelier (1983)

${ }^{2}$ Nesse sentido, nossa abordagem é parecida com aquela de Benjamin Coriat e de Pascal Petit.
} 
trabalho vivo aplicado ao trabalho e ao conhecimento acumulado no passado. Enfim, Marx ressalta a tendência ao aumento da composição orgânica do capital social, a razão entre trabalho vivo e trabalho morto diminuindo com o decorrer do tempo. Nesse caso, estamos na presença de um aumento do estoque de conhecimento por trabalhador, do estoque de informação que o trabalhador tem de "manipular"; esta análise fornece uma explicação alternativa para interpretar essa economia do conhecimento e da informação.

De um ponto de vista econômico, o conhecimento se caracteriza pela não exclusividade, pela não rivalidade e pelo seu caráter cumulativo:

i) A não exclusividade significa que o agente que produz o conhecimento não tem condições de controlar plenamente as modalidades de apropriação desse conhecimento: esse conhecimento produz, intrinsecamente, externalidades positivas de que os diferentes agentes podem apropriar-se. Essas externalidades positivas se relacionam como saberes abertos ${ }^{3}$ (Foray, 2000:80) e com a existência de clubes e de redes também abertos (Herscovici, 2004 (b)). A função de bem estar social depende diretamente do grau de abertura desse clube: quanto maior o grau de abertura, mais importantes as externalidades e mais cumulativo o conhecimento assim produzido.

ii) A não rivalidade se explica pelo fato do conhecimento não ser destruído no ato do consumo: o consumo de um indivíduo não implica que esse bem não possa ser consumido por outros indivíduos. Isso ressalta o caráter indivisivel da oferta.

iii) Finalmente, o caráter cumulativo do conhecimento expressa o fato que a taxa de crescimento da produção do conhecimento depende do nível do estoque inicial; o conhecimento está sendo utilizado como um insumo para produzir mais conhecimento. O conhecimento se caracteriza por rendimentos crescentes, o que constitui os fundamentos das teorias do crescimento endógeno (Romer, 1990).

Nessa economia do conhecimento, existe uma divergência entre o interesse público e os interesses privados: no que diz respeito ao primeiro aspecto, a maximização do interesse coletivo corresponde à produção de externalidades positivas e à difusão gratuita deste conhecimento: à medida que $o$ custo marginal de uso do conhecimento é nulo, a maximização da função de bem estar coletiva implica que seu preço seja, igualmente, igual a zero (Foray, op. cit.:62). Não obstante, essa gratuidade não permite criar os incentivos suficientes para que o setor privado continue a investir na produção de conhecimento: se as externalidades de demanda forem maximizadas, o lucro do produtor de conhecimento seria nulo. Os incentivos para a produção privada de conhecimento fazem com que seja preciso limitar, a partir de um sistema de direitos de propriedade, as modalidades de acesso e de uso desse conhecimento e dessa informação.

\footnotetext{
${ }^{3}$ Este conceito é parecido com o que certos autores chamam de ciência aberta (Orsi, 2002, p. 78) ou de cientific commons (Nelson, 2003).
} 
Valor de uso, valor de troca e assimetrias da informação.

O valor de uso dos bens e serviços é determinado pela quantidade de informação incorporada. Conseqüentemente, o valor de uso depende diretamente (a) dos conhecimentos tácitos de cada consumidor/usuário e (b) dos resultados das aplicações desses conhecimentos tácitos para decodificar as informações contidas nessas mercadorias. No que diz respeito a esse segundo ponto, tendo em vista a complexidade dessas informações, o consumidor não pode avaliar, ex-ante, a utilidade que a mercadoria lhe propiciará. O valor de troca depende da quantidade de informação que é potencialmente utilizável pelo consumidor/usuário.

i) Essas mercadorias são o objeto de modalidades de apropriação cognitiva e socialmente diferenciadas. Os processos socialmente diferenciados de aquisição de conhecimentos tácitos se traduzem por utilidades socialmente diferenciadas.

ii) Essa lógica corresponde aos processos de segmentação da demanda que caracterizam o "pós-fordismo" e a acumulação intensiva que lhe é própria (Herscovici, 2000). Essa segmentação é implementada a partir da quantidade e da complexidade da informação incorporada nas mercadorias.

iii) Nesse caso, os custos de aprendizagem não são mais assegurados pelo produtor. Contrariamente ao que ocorria no período fordista, quando esses custos eram embutidos na própria mercadoria, na lógica pós-fordista, os custos de aprendizagem são implementados fora do mercado e são socialmente diferenciados. As diferentes modalidades concretas de re-apropriação das Tecnologias da Informação e da Comunicação (TIC) e de construção das modalidades de uso (o que corresponde a uma lógica de demand push ou de user driver) podem ser explicadas à luz de tais análises.

iv) Finalmente, essa economia da informação e do conhecimento se caracteriza por importantes assimetrias de informação, da maneira como elas foram definidas por Stiglitz e Grossman (1976). Os bens podem ser assimilados aos experience goods à medida que suas qualidades são realmente conhecidas apenas pela sua utilização pelo consumidor. ${ }^{4} \mathrm{~A}$ informação da qual o consumidor pode dispor é, por natureza, incompleta: o consumidor só poderá avaliar a utilidade real dos bens no próprio ato de consumo, ou seja, quando ele poderá conhecer sua capacidade efetiva para decodificar essas informações. É o nível de adequação entre seus conhecimentos tácitos e as informações contidas nos bens que lhe permite determinar a utilidade efetiva daquele bem. Trata-se, igualmente, de um processo de seleção adversa na medida em que o consumidor não pode determinar, ex-ante, o conjunto das qualidades da mercadoria que ele se propõe a comprar. Essas assimetrias da informação fazem com que esses mercados não sejam eficientes, no sentido de Pareto (Stiglitz e Grossman, 1976). De um modo geral, a multidimensionalidade da informação faz com que (a) não seja possível avaliar ex-ante

\footnotetext{
${ }^{4}$ Neste ponto, minha análise é semelhante àquela de Arena et Ragni (2004, pp. 66 e 83) e Bellon (2004, p. 316).
} 
sua utilidade (b) nem considerar que essa utilidade é a mesma para o conjunto dos consumidores (Herscovici, 2004 (a)).

\section{O DEBATE RELATIVO AOS DPI: A PATENTE CONSTITUI UM FATOR QUE FAVORECE A INOVAÇÃO TECNOLÓGICA?}

\section{A análise em favor das patentes: características e limites}

As diferentes análises de inspiração neoclássica concebem a propriedade industrial como um instrumento capaz de aumentar o ritmo da inovação tecnológica e, conseqüentemente, de intensificar o progresso técnico. A patente é concebida como um meio para desenvolver as incitações e aumentar a produção de inovações, assim como sua taxa de crescimento. Segundo North (1981:164), “a ausência de direitos de propriedade no que diz respeito às inovações permite explicar o progresso técnico lento" que conheciam as sociedades pré-capitalistas. Se a ausência de tais direitos se traduz por uma taxa de rendimento social elevada, a taxa de rendimento privado da inovação é tão fraca que só pode produzir um progresso técnico lento. Em outras palavras, quanto mais "frouxos" os DPI, menos cumulativo se torna o progresso técnico.

Essas análises partem dos seguintes pressupostos: o mercado é a instância social e economicamente eficiente a partir do momento que existe um sistema "sólido" de direitos de propriedade. Por um lado, os direitos de propriedade permitem "converter os ativos em capital" e gerar assim as rendas correspondentes para os detentores desses direitos (Bergh, 2003:265). Por outro lado, a ausência de um sistema eficiente de direitos de propriedade prejudica diretamente a produção de inovação, os ganhos de produtividade e, em última instância, o crescimento (Murphy, Shleifer, Vishny, 1993:413 e 414).

O desenvolvimento das atividades de rent-seeking é concebido como uma conseqüência direta da ausência ou da não eficiência do sistema de direito de propriedade. Os pressupostos implícitos que norteiam esta análise são os seguintes: as atividades de rent-seeking e, mais especificamente, as atividades de rent seeking público (Idem:414), vão diminuir esse bem-estar coletivo, não vão incentivar a inovação e vão diminuir as possibilidades de crescimento econômico. Como mostrarei mais adiante, a modificação da natureza e do papel dos DPI, ao contrário, pode ser assimilada às atividades de rent seeking e não corresponde a um funcionamento eficiente dos mercados.

Seguindo essa análise de cunho neoclássico, os DPI constituem uma renda de monopólio temporária da qual se beneficia o inovador. Por outro lado, a patente é um instrumento que permite divulgar, de uma maneira eficiente, a inovação:

i) Obriga o produtor a tornar pública sua inovação (Lévèque, Menière, 2003:27).

ii) Permite propagar o progresso para o conjunto das empresas, para um custo menor daquele que as empresas teriam de assumir no caso delas 
produzirem uma inovação equivalente ou substituível. Finalmente, elas permitem remunerar o produtor da inovação, de tal maneira que os custos em Pesquisa e Desenvolvimento sejam compensados pela venda de licenças.

iii) $\mathrm{Na}$ ausência de custos de transação, os direitos de propriedade diminuem o excedente do produtor e não do consumidor (Coase, 1960).

Ressaltarei os limites dessas análises a partir (a) das especificidades relativas à natureza econômica do conhecimento, (b) das falhas de mercado características da economia da informação, (c) da modificação da natureza dos objetos sobre os quais esses DPI são aplicados e da função dos DPI nas estratégias das empresas. Analisarei sucessivamente esses pontos para poder refutar a análise microeconômica tradicional da informação e do conhecimento.

\section{A natureza econômica e as falhas de mercado}

Segundo Arrow (2000 (b):88) , é praticamente impossível definir direitos de propriedade sobre a informação: sua não exclusividade, as inúmeras possibilidades de pirataria e de retro-engenharia não permitem controlar todas as modalidades de apropriação da informação e do conhecimento. Por outro lado, a Ciência é um bem patrimonial (Herscovici, 1997) e se caracteriza por sua dupla dimensão pública e privada: as diferentes medidas jurídicas, até o início dos anos 80 , tinham como objetivo limitar as modalidades de apropriação do patrimônio comum. Os DPI representam uma forma institucional específica, ou seja, a codificação de determinadas relações sociais: assim, as modificações recentes em termos de DPI podem ser interpretadas como modificações institucionais que correspondem à lógica de acumulação do pós-fordismo.

Esse debate se relaciona diretamente com o domínio de aplicabilidade dos DPI. Uma invenção pode ser o objeto de uma patente quando ela é útil, ou seja, quando ela apresenta uma utilidade prática e $\operatorname{comercial}^{5}$ (Orsi, 2002:72); até os anos 80, os tribunais americanos, nas suas ações de jurisprudência, limitavam a "patentabilidade" às invenções, ou seja, a aplicações práticas e definidas de certos processos. No entanto, hoje, as modificações do conceito de utilidade se traduzem, de fato, por uma redefinição das fronteiras, por uma ampliação do campo de aplicação dos DPI e, de fato, por uma privatização dos scientific commons e do conjunto dos bens patrimoniais. Processos ligados às combinações genéticas ou aos algoritmos utilizados nos programas informáticos são o objeto de DPI.

Os anticommons (Heller e Eisenberger, 1998) se caracterizam pelo fato do conhecimento ser o objeto de DPI múltiplos; nesse caso, o jogo de mercado pro-

\footnotetext{
${ }^{5}$ Apesar das diferenças conceituais que existem entre o direito europeu e o direito americano, há, desde os anos 80, uma convergência das duas estruturas jurídicas, a partir do modelo americano. No direito europeu, a patente se aplica unicamente a uma invenção, esta sendo definida pelo seu caráter inovador e pelas suas aplicações técnicas identificadas; a legislação das patentes só é aplicável a uma invenção, e não a uma descoberta. No direito americano, esta distinção entre invenção e descoberta não existe mais hoje.
} 
duz externalidades negativas e importantes falhas de mercado. Há um aumento dos direitos de transação relativos à aquisição dos diferentes processos necessários à implementação de uma determinada tecnologia, à medida que os utilizadores têm de negociar esses direitos com vários titulares dos direitos.

Aparecem, igualmente, externalidades de demanda que geram importantes falhas de mercado. Se, para determinado processo tecnológico, há dois titulares de DPI, A e B, e se A diminui o preço relativo à aquisição de direitos, a demanda dos DPI de A vai aumentar; a demanda dos DPI de B vai aumentar também, mesmo se B não diminui seus preços. A existência de externalidades de demanda ressalta as falhas de coordenação que estão surgindo nesse mercado e o equilíbrio sub-ótimo que lhe é ligado. No exemplo utilizado aqui, A não tem interesse em baixar seu preço se B mantém seu preço constante; não haverá queda dos preços dessas patentes. Em todos os casos, haverá uma sub-aditividade dos custos relativos à aquisição desses direitos, na medida em que o preço necessário para utilizar aquela tecnologia será superior àquele que prevaleceria no caso de haver apenas um detentor de direito.

Finalmente, no caso de haver um patrimônio comum ao conjunto dos agentes (conhecimento aberto, meio ambiente etc.), o fato de um agente se apropriar, no âmbito de uma lógica privada, de parte desse estoque diminui o nível do estoque disponível para os outros agentes. Esse comportamento predador só pode gerar uma diminuição do patrimônio comum ao conjunto dos agentes; à medida que essas atividades são cumulativas e seqüenciais, isto se traduz por uma diminuição da taxa de crescimento das invenções e das inovações.

\section{A modificação da natureza dos DPI}

As principais modificações jurídicas que apareceram a partir do início dos anos 80 se traduzem por uma extensão do campo de aplicação dos DPI e dos atores que podem adquirir esses direitos.

No que diz respeito ao primeiro ponto, a jurisprudência americana, imitada pela jurisprudência européia, se modificou radicalmente, ampliando o campo de aplicação dos DPI e modificando a dicotomia tradicional entre o público e o privado, entre conhecimento aberto e conhecimento fechado. Hoje, os DPI são aplicáveis a processos definidos genericamente e cujas aplicações não são previsíveis nem identificáveis (Coriat, 2002 (a):25) (códigos genéticos e algoritmos informáticos). Essa extensão de fronteiras se traduz por um deslocamento dos DPI das aplicações tecnológicas identificadas para os conceitos genéricos dos quais provêm essas inovações (Idem:23). Trata-se de uma privatização dos scientific commons e, conseqüentemente, de uma redefinição da dicotomia privado/público que ameaça o caráter cumulativo do conhecimento. Os últimos acordos concluídos no âmbito da Organização Mundial do Comércio vão nesse sentido: o novo conceito de Trade Related Intellectual Properties não permite mais diferenciar propriedade intelectual e industrial e estende o campo de aplicabilidade dos DPl. O debate relativo à definição da natureza e do campo de aplicação dos DPI é fun- 
damental: as escolhas efetivamente feitas determinarão as modalidades concretas de apropriação social do conhecimento e da informação.

O desenvolvimento do sistema de DPI, da maneira como ele está sendo implementado, se traduz pela exploração e pela privatização de saberes milenares que, de um ponto de vista antropológico, fazem parte da cultura mundial. A extensão da propriedade intelectual para as medicinas tradicionais vai no mesmo sentido: "Os recursos genéticos, uma vez modificados, podem apresentar características que não se encontram na natureza (...)"(OMPI, 2004:2) e, na medida em que esses processos podem ser assimilados a uma invenção, eles podem ser objeto de um direito de propriedade privada. Trata-se de uma acumulação primitiva do conhecimento (Bolaño, 2002) comparável com a acumulação primitiva descrita por Marx.

Paralelamente, certas modificações jurídicas permitem a entrada de novos atores nesse jogo de especulação financeira.

O Bayh-Dole Act permite depositar patentes relativas aos conhecimentos produzidos por instituições públicas e ceder, sob a forma de direitos exclusivos, a exploração dessas patentes para firmas privadas (Coriat, 2002 (b):180). A atribuição desses direitos exclusivos pode ser assimilada a uma estratégia de segredo e não de difusão da inovação, o que reforça os elementos monopolistas.

Por outro lado, a National Association of Securities Dealers torna possível o acesso de empresas deficitárias à bolsa de valores, a partir do momento que elas possuem determinado capital intangível, ou seja, a partir do momento que elas possuem DPI (Coriat, 2003:3).

As condições jurídicas e econômicas são assim reunidas para que se desenvolva uma economia especulativa financeirizada, introduzindo novos atores e estendendo essa lógica para os componentes públicos da Pesquisa. Essas evoluções vão se traduzir por uma modificação da natureza da concorrência e do progresso técnico, assim como das estratégias das empresas e das modalidades de acumulação do capital

\section{AS IMPLICAÇÕES ECONÔMICAS}

\section{As novas formas da concorrência}

DPI e novas formas de concorrência

Todos os estudos empíricos mostram que, de 1980 até hoje, não há uma correlação positiva entre a quantidade de patentes registradas e o progresso técnico, este podendo ser avaliado a partir das despesas em Pesquisa e Desenvolvimento. A um aumento da taxa de crescimento do número de patentes registradas, não corresponde um aumento da taxa de crescimento das despesas em P\&D (Lebas, 2002:252). As teses de inspiração neoclássica não são verificadas à medida que a ampliação dos DPI não se traduz por uma intensificação das incitações a inovar. 
Esse fenômeno se traduz por uma modificação da natureza e da função dos DPI, conforme mostrarei agora; as firmas praticam uma estratégia sistemática de constituição de portfólio de DPI, e isso sem nenhuma relação com a intensificação do progresso técnico. Isto pode ser explicado a partir de dois fatores:

i) a patente não é mais concebida como um meio de se apropriar uma renda de monopólio temporário relativa à inovação tecnológica (Idem:254); o segredo é preferido à difusão da inovação. Quanto mais a patente se relaciona com processos e não com produtos, maior o poder de mercado da empresa que detém esse direito. A implementação desse tipo de barreira à entrada se traduz por uma diminuição da concorrência nesses mercados. As firmas que não alcançaram determinada massa crítica, em termos de DPI, não podem penetrar no mercado: na medida em que os processos tecnológicos que elas querem implementar contêm componentes protegidos, sua entrada é impedida. Essas firmas são objeto de uma estratégia de hold-up por parte das firmas que já atuam no mercado; estas constituem uma rede fechada dentro da qual elas trocam suas patentes; constroem assim barreiras à entrada eficazes e mantêm sua vantagem diferencial em relação às firmas excluídas da rede. ${ }^{6}$ Por outro lado, tais estruturas de mercado se traduzem por um risco maior no que diz respeito ao valor das patentes: o valor de uma patente, por parte de uma firma A, depende das patentes das firmas B, C e D, e das possibilidades dessas impedirem o registro da patente de A. Esse tipo de configuração de mercado se relaciona com a teoria do oligopólio e a teoria dos jogos, à medida que a estratégia desenvolvida por $\mathrm{A}$ depende das expectativas de $\mathrm{A}$ no que diz respeito às estratégias de $\mathrm{B}, \mathrm{C}$ e $\mathrm{D}$. A existência de equilíbrios múltiplos não corresponde a uma situação de ótimo.

ii) Está havendo uma modificação da natureza das rendas de monopólios que esses DPI permitem se apropriar. Na análise tradicional, os DPI permitem a apropriação de rendas diretas de monopólios, estas constituindo o pagamento que corresponde à utilização da inovação. O novo sistema de DPI corresponde às rendas indiretas de monopólio; estas nascem da existência de barreiras à entrada que esses DPI permitem construir e das vantagens concorrenciais que lhe são ligadas.

As implicações em termos de estrutura de mercado

O valor da patente depende diretamente das receitas esperadas que a inovação pode propiciar ao detentor dos direitos. Hoje, conforme mostrei, as patentes se relacionam com processos genéricos cujas aplicações econômicas e tecnológicas são dificilmente identificáveis: conseqüentemente, as receitas potenciais que essa inovação pode gerar são particularmente aleatórias.

Está ocorrendo uma ampliação do poder de monopólio à medida que os DPI não se relacionam mais com aplicações identificáveis de determinada inovação,

\footnotetext{
${ }^{6}$ Encontramos aqui o conceito de rede fechada, no seio da qual circulam informações privadas. Nesse caso, as externalidades são endogeneizadas no seio da rede (Herscovici (2004 (a))
} 
mas sim com o conjunto indefinido das aplicações de determinados processos genéricos científicos ou tecnológicos.

Há, igualmente, um elemento que vem acentuar a incerteza ligada às receitas que essas patentes podem propiciar: à medida que a efetivação de determinada patente, por parte de uma firma $\mathrm{A}$, pode ser bloqueada pelas patentes que $\mathrm{B}$, C e D possuem, as receitas que A pode esperar de sua patente são ainda mais incertas.

Esses mercados se caracterizam pela forte endogeneização das externalidades produzidas pelo progresso técnico, realizada no seio de redes fechadas ou semifechadas. As barreiras à entrada assim construídas limitam as externalidades de oferta e o caráter cumulativo do progresso técnico. Por outro lado, essas estratégias se traduzem por falhas de coordenação, as quais ressaltam o fato que esses mercados não são eficientes.

Rumo a uma economia "solidária”?

Um programa como Linux pode ser chamado de livre pelo fato de se caracterizar por um código aberto, não protegido; suas cópias podem ser disponibilizadas gratuitamente, ou a partir de uma taxa, isso não importa; a "liberdade" reside no fato que o usuário tem acesso ao código fonte e pode modificá-lo, a totalidade dos usuários se beneficiando dessa versão modificada (Stallman:pp. 4 e 7). O aumento do número de usuários pode incentivar as firmas a desenvolver esse tipo de programas livres; as cópias são pagas mas não existe um direito de propriedade relativo à arquitetura do programa. Esse tipo de mecanismo semisolidário permite questionar os conceitos tradicionais de pirataria, de autoria, e mostra como um sistema semi-solidário permite remunerar as atividades de pesquisa (Ibid:14) e manter o caráter cumulativo do conhecimento assim produzido. A economia desse tipo de programa se traduz por uma modificação da dicotomia entre o mercantil e o não mercantil.

O desenvolvimento desse tipo de economia permite colocar certos questionamentos, de ordem sociológica e econômica.

i) Em relação à produção de programas com códigos fechados como os da Microsoft, por exemplo, os programas livres representam, sem dúvida, uma intensificação da concorrência, pelo simples fato de eliminar as diferentes barreiras à entrada. Isso se explica a partir do fato do código do programa ser aberto: ao segredo industrial relativo aos programas tradicionais, se opõe a liberdade de acesso e de modificação dos programas livres.

As implicações econômicas são as seguintes:

(a) O clube que corresponde a esse tipo de economia é intrinsecamente aberto e inclusivo. As externalidades de demanda aparecem a partir do momento que a qualidade do serviço ofertado é diretamente proporcional ao número de usuários. Por outro lado, pelo fato de não haver exclusão pelos preços, haveria uma maximização do bem estar social.

(b) A coordenação dos agentes econômicos e a estabilidade do sistema 
são asseguradas por mecanismos que relevam da economia das instituições e/ou das convenções, e não pelos sistemas de preços.

(c) A informação que circula nessas redes é um bem totalmente indivisível, consumido por todos na sua integralidade.

ii) Há, nesse sentido, uma publicização da informação, no sentido habermassiano da palavra: ela deixa de ser secreta para se tornar objeto da discussão pública e de re-apropriações múltiplas.

De um modo mais geral, a economia das redes eletrônicas permite o surgimento de espaços concorrenciais, os quais podem ameaçar a estabilidade dos oligopólios e dos monopólios:

i) o exemplo dos programas livres é característico desse fenômeno.

ii) a existência de hackers tem de ser interpretada da mesma maneira; o fato deles poderem acessar determinadas informações privadas é incompatível com o funcionamento atual do sistema.

iii) a produção de vírus representa, igualmente, uma ameaça em relação à regulação atual do setor.

iv) o desenvolvimento de todas as formas de pirataria, as legais e as ilegais, vai no mesmo sentido.

v) seria possível formular o mesmo tipo de observações no que diz respeito às obras musicais disponíveis na rede em MP3: a generalização desse tipo de modalidade de apropriação ameaça a economia do setor da edição fonográfica.

Os componentes interativos, concorrenciais, descentralizados e cooperativos entram em conflito com as estruturas oligopolistas/monopolistas desses mercados e tornam necessárias novas modalidades de regulação do setor. É interessante observar que essa dialética sempre caracterizou as indústrias ligadas à Cultura e à Informação: a pirataria e a cópia privada têm de ser concebidas como processos que desestabilizam a economia do setor; da mesma maneira, as relações entre o cinema e a televisão, durante muito tempo, se caracterizaram pela distorção entre as modalidades de consumo dos filmes e suas modalidades de financiamento (Herscovici, 1995)

Os trabalhos que tratam da "community governance" (Bowles, 2001) mostram que os problemas de coordenação podem ser resolvidos a partir de modalidades de produção e de distribuição semi-solidárias: as comunidades constituem espaços sociais nos quais os diferentes processos de socialização são implementados, clubes nos quais as diferentes externalidades são endogeneizadas. Os problemas ligados ao moral hazard e à seleção adversa podem ser resolvidos de uma maneira mais eficiente do que pelo mercado ou pela intervenção do Estado. Conforme mostraram Stiglitz e Akerlof, o sistema de preços não tem condições de fornecer o conjunto das informações relativo aos produtos e serviços, e o mercado não é, social e economicamente, eficiente. De um ponto de vista mais geral, o mercado não pode "capturar" o conjunto das informações relativas à troca e às implicações ligadas aos contratos estabelecidos entre os diferentes agentes (Bowles e Hammerstein 2003:155). É possível observar o mesmo tipo de limitações no que diz respeito à intervenção do Estado; já no que diz respeito aos bens pú- 
blicos, o indivíduo racional não tem interesse em revelar suas preferências, conforme ressalta o dilema do free-rider.

Esses mecanismos de "governança" constituem, assim, modalidades eficazes de coordenação das atividades dos diferentes agentes econômicos: permitem coordenar a atividade de produção e implementar novas modalidades de apropriação social dos bens e serviços assim produzidos. No caso específico dos programas livres, permitem internalizar as externalidades do conhecimento e manter o caráter cumulativo dessas atividades.

Finalmente, esse tipo de mecanismo está ligado a um processo de destruição parcial da forma mercadoria: no âmbito de uma análise em termos de economia institucional, à medida que o mercado não é uma instância autônoma e auto-reguladora, o desenvolvimento das formas não mercantis é necessário para suas modalidades concretas de funcionamento. ${ }^{7}$ Não obstante, a contradição provém do fato que esses desenvolvimentos são, por natureza, limitados. ${ }^{8}$

Esse debate, relativamente complexo, pode ser concebido a partir de duas ópticas: (a) as modalidades de criação do valor se relacionam diretamente com a produção de mercadorias e, neste caso, os gastos ligados à manutenção dessas instituições são, por natureza, improdutivos ou (b) ao contrário, no âmbito dos limites da forma mercadoria, as próprias modalidades de criação e de apropriação do valor se modificaram. Enquanto a primeira tese implica em "punções parasitárias" (Chesnais, 2001) do setor improdutivo sobre o valor criado pelo setor produtivo, a segunda torna necessária uma redefinição da natureza do trabalho produtivo e das modalidades de criação e de apropriação social do valor (Herscovici e Bolaño, 2005; Herscovici, 2006).

\section{A modificação das relações macroeconômicas}

\section{Capital intangível, capital imaterial e modificação da natureza do capital}

O capital intangível, ou seja, todas as formas de capital imaterial, é um dos conceitos centrais da análise econômica, a partir dos anos 70: as teorias do capital humano e do crescimento endógeno ressaltam o papel fundamental das atividades de formação e de pesquisa e desenvolvimento no processo de crescimento econômico. Da mesma maneira, o desenvolvimento de todas as formas de capital financeiro e a formação de bolhas financeiras colocam o problema relativo à natureza e à medida desse tipo de capital. Esta problemática lembra, por certos aspectos, a controvérsia de Cambridge do final dos anos 60.

No âmbito de uma análise clássico-marxista, o capital intangível representa, sem dúvida, uma forma de capital fictício: (a) não representa uma quantidade de

\footnotetext{
${ }^{7}$ A este respeito, ver Karl Polanyi (1983).

${ }^{8}$ A este respeito, Adam Smith sublinhava a importância de determinadas "condições gerais” para o mercado poder funcionar concretamente.
} 
trabalho cristalizado, segundo Marx, ou trabalho passado, como pensava Ricardo; (b) por outro lado, seu valor monetário não tem nenhuma relação com seu valor "real”. Esse capital é puramente fictício à medida que, no âmbito de uma lógica especulativa, seu valor não é determinado em função da renda real da empresa, mas das expectativas de renda (Le Capital, livre III:492); (c) neste sentido, é possível afirmar que “(...) o preço deixa de expressar o valor (...)” (Le Capital, Livre I:107) à medida que esse preço se determina independentemente da quantidade de trabalho social gasta direta e indiretamente na produção dessa mercadoria.

As receitas ligadas à valorização econômica da informação (e isto valeria para todas as outras formas de capital imaterial) se determinam independentemente dos custos em trabalho necessários (Bellon, 2004:308): (a) o caráter particularmente aleatório de sua valorização não permite determinar uma correlação entre os custos e as receitas, ${ }^{9}$ (b) tendo em vista a complexidade dos processos de produção implementados e o caráter essencialmente cumulativo da produção desse tipo de bens, não é mais possível determinar a quantidade direta e indireta de trabalho necessária para sua produção (Bolaño e Herscovici, 2005).

Trata-se, igualmente, de uma economia intrinsecamente especulativa: nesta, o preço é determinado em função das expectativas de receitas que esse capital pode, potencialmente, produzir; no âmbito de uma lógica keynesiana, o valor do capital depende de sua eficiência marginal, ou seja, das receitas previstas que o investimento geraria durante sua vida útil (Keynes, 1990). No entanto, na Teoria Geral, Keynes opõe os investimentos especulativos aos investimentos produtivos (Idem) e ressalta, no âmbito de uma economia de "cassino", os perigos ligados ao desenvolvimento desse tipo de investimento. Se, no âmbito de uma análise (pós) keynesiana, o valor do investimento depende das receitas que ele pode gerar e se o universo se caracteriza pela incerteza, no sentido definido por Knight, o valor do investimento produtivo é, por natureza, diferente daquele do investimento especulativo:

i) no que diz respeito ao investimento produtivo, seu valor é calculado em função das receitas previstas durante a totalidade de sua vida útil: esse valor se relaciona com uma perspectiva de longo prazo e o investimento é concebido como um ativo que apresenta uma liquidez fraca. Por outro lado, quanto ao capital produtivo, o investidor pode determinar sua vida útil, o que não é o caso no que diz respeito ao capital intangível; esse elemento vem intensificar a incerteza ligada à valorização do capital especulativo financeiro no curto prazo. Essas expectativas se caracterizam pela sua instabilidade, o que explica a volatilidade desses capitais.

ii) Ao contrário, o investimento especulativo se define numa perspectiva de curto prazo e se caracteriza por uma liquidez quase imediata. A especulação consiste em prever, antes do público, as evoluções do mercado.

\footnotetext{
${ }^{9}$ Neste sentido, trata-se de uma lógica de protótipo comparável com aquela das produções culturais (Herscovici, 1995).
} 
iii) Finalmente, enquanto, a partir do multiplicador de despesas, o aumento do investimento produtivo se traduz por um aumento da produção e do emprego, ao aumento do investimento especulativo não correspondem evoluções desse tipo.

A "nova economia" é, por natureza, uma economia especulativa: o capital não é concebido em função das receitas que ele pode "normalmente" gerar, mas a partir das rendas de monopólio diretas e indiretas que os DPI permitem se apropriar, num ambiente que se caracteriza por uma incerteza forte. Em função das modificações da natureza dos DPI, essas rendas de monopólio são virtuais e particularmente aleatórias. Do ponto de vista keynesiano, trata-se de uma modificação da natureza das expectativas; a partir de uma abordagem clássico-marxista, isto deve ser interpretado como uma modificação da natureza do capital.

A análise das bolhas financeiras racionais mostra que elas aparecem em mercados cujo valor fundamental dos ativos é dificilmente determinável (Frois, 1991:56). Esses mercados se caracterizam pelo fato do preço do ativo ser determinado a partir de seu preço esperado; nesse sentido, há uma auto-realização das expectativas. Enfim, na medida em que esse movimento de alta do valor dos ativos não é infinito, a crise se traduz pelo estouro dessas bolhas especulativas.

Qual é a natureza dessas bolhas "tecnológico-financeiras"? Em que medida esses mercados se caracterizam por uma incerteza forte?

A incerteza econômica provém da natureza desses ativos; conforme já mostrei, não é possível prever, com um certo grau de confiança, as receitas que eles podem gerar. Contrariamente ao que afirmam as teorias fundamentalistas, não é possível determinar o valor fundamental desse tipo de ativo: conseqüentemente, não é possível determinar o desvio entre o valor real desses ativos e seu valor fundamental. Uma explicação alternativa é fornecida pelo conceito keynesiano de convenção (Boucher, 2004:299): este se define como uma crença coletiva que permite elaborar expectativas a partir da opinião "média" do mercado, à medida que o estado atual se perpetuar no futuro (Keynes, 1990:126). A lógica especulativa, como aquela da NASDAQ, por exemplo, pode ser analisada desta maneira: a especulação se auto-alimenta, a partir de um jogo de mimetismo (Orléan, 1999). A crise marca o fim da convenção existente e a emergência de uma nova convenção (Herscovici, 2004 (c)).

A incerteza tecnológica se explica a partir de dois fatores: (a) a obsolescência cada vez mais veloz das tecnologias diminui a vida útil da inovação e seu valor econômico, e (b) as estratégias desenvolvidas pelas firmas tornam mais aleatória a implementação de uma inovação.

É igualmente interessante observar que o desenvolvimento desses ativos imateriais não mantém nenhuma relação de proporcionalidade com o estoque de capital tangível das empresas (Boucher, op. cit:290). O valor das empresas, na bolsa, depende cada vez mais de seu capital intangível: DPI, imagem de marca, conhecimento tácito de seus funcionários (Arrow, 2000 (b):90). Conforme visto, o valor desse capital intangível é por natureza particularmente instável. Assim, essa economia com dominância financeira é, também, instável e não tem condi- 
ções de constituir um novo modo de regulação viável no médio e longo prazo (Chesnais, 2001; Coriat, 2003).

Essas reflexões permitem colocar, de maneira adequada, os problemas relativos à medida e à natureza do valor das diferentes formas de capital intangível; permitem também fornecer uma explicação alternativa para o paradoxo de Solow: em que medida os sistemas de contabilidade social têm condições de avaliar corretamente as diferentes formas de capital intangível? Tendo em vista o caráter cumulativo e seqüencial da produção de conhecimento, em que medida as avaliações dos ganhos de produtividade do trabalho são confiáveis (Petit, 2003)?

As modificações da natureza do progresso técnico

A essas evoluções corresponde uma modificação da natureza do progresso técnico e das externalidades que lhe são ligadas. As novas formas da concorrência se traduzem por modalidades diferenciadas de apropriação das externalidades produzidas pela produção de conhecimento. Nessa perspectiva, o progresso técnico é seletivo e assimétrico, gera importantes falhas de coordenação e não permite maximizar a eficiência estática e dinâmica. Finalmente, essas estratégias oligopolistas se traduzem por um aumento importante dos custos de transação.

A partir desses elementos, o impacto agregado do progresso técnico é relativamente fraco, conforme ressaltam as diferentes pesquisas empíricas:

i) a ausência de correlação positiva entre a taxa de equipamento das empresas em TIC e a taxa de crescimento da produtividade do trabalho e do PIB mostra claramente que os efeitos agregados do progresso técnico são relativamente fracos. Esses elementos fornecem uma explicação alternativa do paradoxo de Solow.

ii) Não é possível assimilar os setores ligados às TIC e às biotecnologias com setores motores, no sentido schumpeteriano. Esses setores não têm condições de fornecer o impulso necessário para implementar um novo ciclo longo de crescimento: seus efeitos diferenciados sobre o conjunto das firmas não permite criar o impacto necessário para gerar tal efeito (Petit, 2002).

iii) Finalmente, o aumento da velocidade do progresso técnico e a obsolescência resultante, vão no mesmo sentido:

(a) O sistema não pode se estabilizar criando as instituições necessárias para maximizar, do ponto de vista macroeconômico, as externalidades ligadas ao progresso técnico: a temporalidade tecnológica e econômica do progresso técnico se torna incompativel com sua temporalidade institucional. Novamente, o progresso técnico não permite criar as condições necessárias a uma nova longa fase de crescimento.

(b) Da mesma maneira, a eficiência dos processos de aprendizagem é diminuída: a obsolescência do conhecimento necessário aos diferentes métodos de produção diminui consideravelmente a taxa de rendimento dos processos de aprendizagem. 


\section{CONCLUSÃO}

A extensão das lógicas de mercado às atividades imateriais tornou necessárias modificações institucionais importantes relativas à legislação em termos de DPI e às diferentes formas de concorrência.

No entanto, o problema consiste em saber se essas novas formas institucionais são compatíveis com o regime de acumulação atual, o qual se caracteriza pela sua dominante financeira (Coriat, 2003). Os elementos levantados neste trabalho permitem responder negativamente: os DPI não permitem maximizar as externalidades relativas à produção de informação e de conhecimento, as modalidades da concorrência geram externalidades negativas e se traduzem por um custo social importante.

Finalmente, essas evoluções institucionais se traduzem por uma modificação da natureza do progresso técnico, o que fornece elementos para explicar o paradoxo de Solow e a fase de crescimento lento que conhecem a maior parte das economias capitalistas hoje.

\section{REFERÊNCIAS BIBLIOGRÁFICAS}

ABRAHAM-FROIS, G. (1991) Dynamique Economique, 7ème édition, Dalloz, Paris.

ARENA, R.; RAGNI, L.(2004) “Dynamique concurrentielle et marchés numériques”, in Nouvelle Économie. Organisations et modes de coordination. Ouvrage coordonné par Adel Bem Youssef et Ludovic Ragni, L’Harmattan, Paris.

ARROW, K. (2000 (a)) "De la rationalité de soi et des autres dans un système économique", in Théorie de l'Information et des organisations. Edité et présenté par Thierry Granger, Dunod, Paris. (2000 (b)) L'économie de l'information: un exposé", in Théorie de l'Information et des organisations, op. cit.

BELLON, B. (2004) “Quelques implications stratégiques de l'économie de l'information”, in Nouvelle Économie. Organisations et modes de coordination. Ouvrage coordonné par Adel Bem Youssef et Ludovic Ragni, L’Harmattan, Paris.

BERG, R. van den (2003) "Property Rights and the Creation of Wealth", American Law and Economics Review, 5 (1).

BOLAÑO, C. (2002) “Trabalho intelectual, comunicação e capitalismo. A reconfiguração do fator subjetivo na atual reestruturação capitalista", Revista da Sociedade Brasileira de Economia Política 11 , dezembro.

BOUCHER, C. (2004) "Révolutions technologiques et bulles financières", in Nouvelle Économie. Organisations et modes de coordination. Ouvrage coordonné par Adel Bem Youssef et Ludovic Ragni, L'Harmattan, Paris.

BOWLES, S.; HAMMERSTEIN, P. (2003) Does market Theory Apply to Biology?, acessado no site www.santafe.edu/sfi/publications Working-Papers./03-04-026, $1^{\circ}$ de julho de 2004.

BOWLES, S.; GINTIS, H. (2001) Social Capital and Community Governance, acessado no site www.santafe.edu/sfi/publications Working-Papers./03-04-027, $1^{\circ}$ de julho de 2004.

BOURDIEU, P. (2000) Les structures sociales de l'Economie, Seuil, Paris.

CHESNAIS, F. (2001) "Nova economia: uma conjuntura específica da potência hegemônica no contexto da mundialização do capital", Revista da Sociedade Brasileira de Economia Política, dezembro.

COASE, R. H.(1960). "The problem of social cost”, Journal of Law and Economics, 3. 
CORIAT, B. (2002 (a)) "Le nouveau régime américain de la propriété intellectuelle - Contours et caractéristiques clés”, Revue d'Economie Industrielle 99, 2ème trimestre, Paris.

(2002 (b)). 'Du 'super 301' aux trips: la vocation impériale du nouveau droit américain de la propriété intellectuelle", Revue d'Economie Industrielle 99, 2ème trimestre, Paris.

(2003) "Droits de propriete intellectuelle, marches financiers et innovation. Une configuration soutenable?" In La lettre de la régulation 45, Juillet, Paris.

DENIS, H. (1974) Histoire de la Pensée Economique, Presses Universitaires de France, Paris.

FAVEREAU, O. (1990) "L'économie des conventions: son objet, sa contribution à la science économique”, Problèmes économiques 2167, 21 Mars, La Documentation Française, Paris.

FORAY, Dominique (2000). L'économie de la connaissance, La Découverte, Paris.

GROSSMAN, S.J.; STIGLITZ, J.E. (1976) "Information and Competitive Price system", American Economic Review, 66 (2).

HELLER, M.; EISENBERG, R. (1998), “Can Patent Deter Inovation? The Anticommons Trady in Biomedical Research", in Science, Vol. 29.

HERSCOVICI, A. (1995) Economia da Cultura e da Comunicação, Fundação Ceciliano Abel de Almeida/UFES, Vitória.

(1997) “Economie des réseaux et structuration de l'espace: pour une Economie de la Culture et de la Communication”, in Sciences de La Société, Toulouse, v. 40.

(2000) "Informação, mercado e regulação macroeconômica. Estatuto teórico da informação, e função das novas tecnologias da informação e da comunicação no capitalismo contemporâneo", in Revista da Sociedade Brasileira de Economia Política, n. 7, dezembro, Rio de Janeiro.

(2002) Dinâmica macroeconômica: uma interpretação a partir de Marx e de Keynes, EDUC/EDUFES, São Paulo.

(2004 (a)) "Economia da informação, redes eletrônicas e regulação: elementos de análise” Revista de Economia Política, v. 24, n.1, São Paulo.

(2004 (b)) Information, société en réseau et nouvel espace public. Réflexions à propos des modalités de réappropriation sociale de l'Information et de l'émergence de nouvelles formes institutionnelles, texte présenté au Colloque International TIC et inégalités: Les Fractures Numériques, 18 et 19 Novembre, Paris.

(2004 (c)) "Irreversibilidade, incerteza e teoria econômica reflexões a respeito do indeterminismo metodológico e de suas aplicações na ciência econômica”, Estudos Econômicos (IPE/USP), São Paulo, 34 (4).

(2006) Conhecimento, capitalismo imaterial e trabalho: alguns elementos de análise, mimeo, UFES, Vitória.

HERSCOVICI, A.; BOLAÑO, C.(2005) “A crítica da economia política da informação e do conhecimento", artigo apresentado no X Encontro Nacional da Sociedade Brasileira de Economia Política, Campinas.

KEYNES, J. M. (1990) A teoria geral do emprego, do juro e da moeda, Atlas, São Paulo.

LEBAS, C. (2002) "Fonctionnement, transformation et tensions du système de brevet-Les implications du "cours pro-brevet" à la lumière des études empiriques récentes", in Revue d'Economie Industrielle n.99, 2ème trimestre, Paris.

LEVEQUE, F.; Menière, Y. (2003) Économie de la Propriété intellectuelle, La Découverte, Paris.

MARX, K. (1893) Le Capital, Editions Sociales, Paris, 1972, Livres I et III.

MURPHY, K. M.; SHLEIFER A.; VISHNY, R. W. (1993) “Why is rent-seeking so costly to growth", American Economic Review, 83 (2), May.

NELSON, R. (2003) Markets and the Scientific Commons, WP, Columbia University.

NORTH, D. C. (1981) "Structure and change", in Economic History, Norton, New York.

ORLEAN, A. (1999) Le pouvoir de la finance, Odile Jacob, Paris.

ORSI, F. (2002) "La constitution d'un nouveau droit de proriété intellectuelle sur le vivant aux ÉtatsUnis: origine et signification d'un dépassement de frontière", in Revue d'Economie Industrielle $n .99$, 2ème trimestre, Paris. 
PETIT, P. (2003) Large network services and the organisation of contemporary capitalism, presented to the workshop Globalization and diversity of Capitalism/New concepts for a Post-Neo-Liberal Era, London School of Economics, June 23rd and 24th 2003.

(2002) "Les temps de la nouvelle économie", in Observateur International de la productivité, n. 4, Printemps 2002.

POLANYI, K. (1983) La Grande transformation. Aux origines politiques et économiques de notre temps, Editions Gallimard, Paris.

RALLET, A. (1999) “A teoria das convenções segundo os economistas”, Nexos I (2), dezembro, Salvador.

ROMER, P. (1990) "Endogenous technological change", Journal of Political Economy, 98 (5).

STALLMAN, R. (2000) "O projeto GNU” in Data GramaZeroZero - Revista de Ciência da Informação - n.1 fev. 